\title{
Trimethoprim: laboratory and clinical studies
}

\author{
J. H. DARRELL, L. P. GARROD, AND PAMELA M. WATERWORTH \\ From the Department of Bacteriology, Royal Postgraduate Medical School, London
} SYNOPSIS Trimethoprim is a synthetic compound which arrests the step in bacterial purine synthesis
immediately succeeding that interfered with by sulphonamides.
Acting alone it inhibits the growth of a wide range of bacteria in generally much lower concen
trations than sulphonamides. Its action with a sulphonamide is strongly synergic and bactericidalo
Studies are described of suitable cultural conditions, methods of testing sensitivity, and acquired
resistance.

Some clinical results of its use are reported in respiratory tract infections, Gram-negative septi caemia, and urinary tract infections, and further therapeutic possibilities are discussed.

Trimethoprim (2,4,-diamino-5-(3', 4', 5'-trimethoxybenzyl)-pyrimidine) is one of a series of compounds first fully described by Roth, Falco, Hitchings, and Bushby (1962) although their study was begun 10 years earlier than this. They possess both antimalarial and antibacterial activity, the former being highest in pyrimethamine and the latter in trimethoprim. This substance is a potent inhibitor of dihydrofolic acid reductase, which is responsible for the conversion of dihydrofolic to tetrahydrofolic acid, a stage in a sequence leading to the synthesis of purines and ultimately of DNA. This stage immediately follows that blocked by sulphonamides:

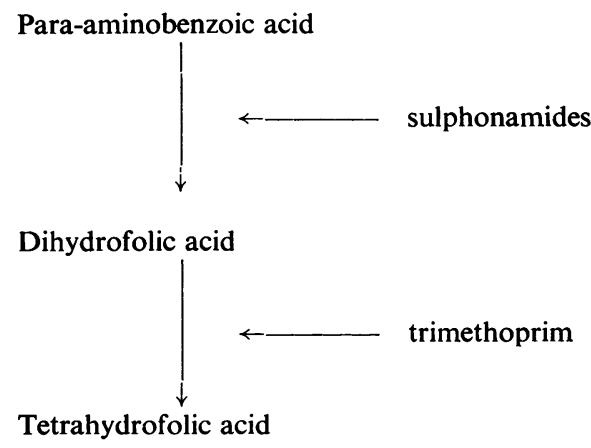

It is hence not surprising that trimethoprim and sulphonamides have been found to exert a strongly synergic effect.

Trimethoprim fortunately has a far lower affinity for the corresponding mammalian enzyme, and there has been very little evidence of interference Received for publication 29 December 1967. with folic acid metabolism following administration to animals and man. The way was therefore clear. for exploiting what appeared to be a highly proso mising therapeutic combination in the clinical fielde Although a few investigators are now convinced of its value, little has been published on the subject Noall, Sewards, and Waterworth (1962) reportecos the successful treatment of a single case of Proteu. septicaemia; another was described by Cooper and Wald (1964). Schneider, Schwarzenberg, Caltan Schlumberger, Amiel, and Mathé (1965) also studieç the treatment of Proteus infections in the urinary tract and elsewhere. Thus for five years the only reports of therapeutic use concerned infection by only one organism out of many which should be susceptible? Some contributions towards filling this gap have recently been made by Csonka and Knight (1967) who describe the successful treatment of gonorrhoea? and by Drew, Hughes, and Jenkins (1967) and Fowle, Drew, Hughes, and Cassell (1967) in brief communications on the treatment of bronchial infections.

So small a literature does scant justice to a new chemotherapeutic agent of considerable interes? and much wider promise. Moreover there is nof readily accessible publication giving a generat account of the properties of trimethoprim and of its antibacterial activity as ascertainable in vitro. It is the purpose of this paper to provide this, togethec with some new observations and a short account of clinical experience with the drug.

The choice of a sulphonamide for in vitro studies of combined action is almost immaterial. Sulphame thoxazole (Gantanol) is regarded as the mos $\overrightarrow{\mathbb{D}}$ suitable for clinical use, mainly because its curve of 
blood concentrations and rate of elimination correspond most closely to those of trimethoprim. In the present experiments its near relative sulphafurazole (Gantrisin) was preferred for its higher solubility.

\section{STUDIES IN VITRO}

MATERIALS AND METHODS Trimethoprim is a colourless crystalline substance, only slightly soluble in cold water. For the experiments in vitro it was converted to the isethionate by adding sufficient normal isethionic acid to bring a suspension containing $10 \mathrm{mg}$ per $\mathrm{ml}$ into solution. The lactate, now available for parenteral use, is more soluble ( $>25 \mathrm{mg} / \mathrm{ml}$ ) and is suitable for laboratory work.

The strains of bacteria used were mostly recent isolates from clinical specimens in this department, but some had been maintained for varying periods. The source of strains of a few species obtained from elsewhere is acknowledged later.

For the determination of minimum inhibitory concentrations (MIC) the plate dilution method was used. Drug solutions to produce concentrations in the medium differing by two-fold, and based on $1 \mu \mathrm{g} / \mathrm{ml}$, were added in a volume of $1 \mathrm{ml}$ to $19 \mathrm{ml}$ melted and cooled diagnostic sensitivity test (DST) agar (Oxoid) containing 5\% lysed horse blood, and areas on these plates were inoculated with a $2 \mathrm{~mm}$ loopful of diluted broth culture (dilution $1 / 100$ for most organisms). In later experiments a multiple inoculator (Steers, Foltz, and Graves, 1959) was used, permitting simultaneous inoculation with suspensions of 32 bacteria. This admirable device enables such experiments to be set up in much less time than it takes later to record them.

MIC OF TRIMETHOPRIM ALONE These results are given in Table I. It can be seen that trimethoprim has a generally much higher activity than sulphonamides, many of its MICs being well under $1 \mu \mathrm{g} / \mathrm{ml}$ whereas that of sulphafurazole in exactly parallel tests, even for fully sensitive species, was usually above this level. Str. pyogenes and pneumoniae are consistently sensitive, and even more so but with more variation in Str. faecalis, in strong contrast to its high degree of resistance to sulphonamides. Staph. aureus is also consistently and highly sensitive, although none of these strains was inhibited by less than $4 \mu \mathrm{g} / \mathrm{ml}$ of sulphafurazole and five of them only by $1024 \mu \mathrm{g} / \mathrm{ml}$. $H$. influenzae is also sensitive (but $H$. pertussis much more resistant). Neisseria spp., notably $N$.gonorrhoeae, are decidedly less sensitive to trimethoprim than to sulphafurazole: that this does not present synergy between them will be seen later.

Among enterobacteria Salmonella and Shigella spp. are consistently sensitive, as are all species of Proteus to a slightly lesser degree. Klebsiella spp. are also usually sensitive, but $P$ s. aeruginosa much more resistant.

MIC OF TRIMETHOPRIM + SULPHAFURAZOLE These were determined in the same way, three series of plates being inoculated, containing a suitable range of concentrations of each drug alone and of the two together in an appropriate ratio. It may be said at once that in almost every experiment with an organism sensitive to both drugs, synergy was demonstrated in the sense that an independently subinhibitory concentration of one reduced the MIC of the other, commonly eight-fold but often more. As an example, a strain of Str. pneumoniae was inhibited by $32 \mu \mathrm{g} / \mathrm{ml}$ of sulphafurazole, and by $1 \mu \mathrm{g} / \mathrm{ml}$ trimethoprim acting alone but by 0.12 $\mu \mathrm{g} / \mathrm{ml}$ in the presence of sulphafurazole in a 10:1 ratio (i.e. actually $1.2 \mu \mathrm{g} / \mathrm{ml}$ ). Thus there was an eight-fold potentiation of the action of trimethoprim

T A B L E I

MIC OF TRIMETHOPRIM

\begin{tabular}{|c|c|c|c|c|c|c|c|c|c|c|c|c|c|c|}
\hline \multirow[t]{2}{*}{ Species } & \multirow{2}{*}{$\begin{array}{l}\text { Total } \\
\text { No. }\end{array}$} & \multicolumn{12}{|c|}{ Numbers Inhibited by $(\mu \mathrm{g} / \mathrm{ml})$} & \multirow{2}{*}{$\begin{array}{l}\text { No End } \\
\text { Point }\end{array}$} \\
\hline & & 0.03 & 0.06 & 0.12 & 0.25 & 0.5 & 1 & 2 & 4 & 8 & 16 & 32 & 128 & \\
\hline Staph. aureus & 18 & & & 5 & 12 & 1 & & & & & & & & \\
\hline Str. pyogenes & 14 & & & & & 10 & 4 & & & & & & & \\
\hline Str. pneumoniae & 14 & . & & & & 7 & 4 & & 3 & & & & & \\
\hline Str. faecalis & 30 & & 2 & 11 & 9 & 3 & 4 & & & & & & & $>4(1)$ \\
\hline Cl. welchii & 3 & & & & & & & & & 1 & 1 & 1 & & \\
\hline N. gonorrhoeae & 18 & & & & & & & & & 1 & 4 & 10 & 2 & $>64(1)$ \\
\hline$N$. meningitidis & 13 & & & & & & & 1 & 2 & 3 & 5 & 2 & & \\
\hline N. catarrhalis & 10 & & & & & & & & & 5 & 3 & & 1 & $>128(1)$ \\
\hline H. influenzae & 29 & 3 & 9 & 14 & 3 & & & & & & & & & \\
\hline H. pertussis & 6 & & & & & & & & & & 2 & 2 & & $>128(2)$ \\
\hline Bacteroides & 12 & & & & & & & & 1 & 4 & 4 & $\overline{3}$ & & $>32(2)$ \\
\hline Esch. coli & 16 & 2 & 7 & 7 & & & & & & & & & & \\
\hline Klebsiella spp. & 10 & & 1 & 1 & 4 & 2 & & 1 & & & 1 & & & \\
\hline Salmonella spp. & 14 & & 6 & 5 & 3 & & & & & & & & & \\
\hline Shigella spp. & 17 & 1 & 2 & 2 & 6 & 6 & & & & & & & & \\
\hline Pr. mirabilis & 14 & & & & & 4 & 6 & 3 & 1 & & & & & \\
\hline Pr. morgani & 10 & & & & & 1 & 6 & 3 & & & & & & \\
\hline Pr. rettgeri & 8 & & & & & 2 & 3 & 2 & & 1 & & & & \\
\hline Ps. aeruginosa & 9 & & & & & & & & & & & 2 & 4 & $512(3)$ \\
\hline
\end{tabular}


by a concentration of sulphafurazole only $1 / 25$ th of its independent MIC.

For the sake of brevity the results of many such experiments are stated in a much condensed form in Table II, in terms of degrees of potentiation of trimethoprim by sulphafurazole. These degrees vary among different strains of a species according to their sensitivity to the individual drugs. The degree of potentiation is highest in $N$. gonorrhoeae, and very high in all species of Proteus except Pr. rettgeri. It is four- to eight-fold for most strains of staphylococci, streptococci, pneumococci, $H$. influenzae, and Esch. coli. For some of these organisms, notably the two last-named, potentiation would probably be greater were the ratio used more nearly proportional to the MIC of the two drugs.

It should be noted that the same sulphonamidetrimethoprim ratio was not employed in all tests. In the majority it was 9:1 but for $N$. gonorrhoeae it was $1: 3$, since this organism is much more sensitive to sulphonamides than to trimethoprim. For sulphonamide-resistant strains of Staph. aureus and Proteus spp. it was respectively 2000:1 and 1000:1: these experiments were done simply to prove that a synergic effect is exerted when concentrations related to the MIC are combined, but it is recognized that such sulphonamide concentrations are not attainable in vivo. The synergic effect on Ps. aeruginosa is presumably only of academic interest, since high concentrations of both drugs are required.

ACQUIRED RESISTANCE It is clearly important to know whether bacteria are capable of becoming resistant to trimethoprim, whether alone or in the presence of a sulphonamide.

This was first studied by serial transfer of a light inoculum on ditch plates, and little change in the MIC was produced even by 25 transfers. On the 은 other hand, only five transfers of a heavy inoculum $\overrightarrow{\vec{F}}$ in rising concentrations in broth produced the con- $\stackrel{5}{?}$ siderable changes shown in Table III. Trimethoprim alone and trimethoprim + sulphafurazole $(1: 10) \frac{\text { 을 }}{\bar{s}}$ were added to the training medium, and after training $\vec{\Phi}_{\bar{\Phi}}$ the MIC of both trimethoprim and of the mixture $\varnothing$ was determined. In parallel experiments with sulpha- के furazole alone no change in the MIC was observed. $\overrightarrow{0}$

\section{T A B L E I I I}

RESULTS OF TRAINING TO RESISTANCE BY TRANSFERS OF A HEAVY INOCULUM IN BROTH

\begin{tabular}{|c|c|c|c|c|}
\hline \multirow{3}{*}{$\begin{array}{l}\text { Drug in training medium } \\
\text { Increase in resistance to }\end{array}$} & \multicolumn{4}{|c|}{ Fold Increase in MIC } \\
\hline & \multicolumn{2}{|c|}{ Trimethoprim } & \multicolumn{2}{|c|}{$\begin{array}{l}\text { Trimethoprim }+ \\
\text { Sulphonamide }\end{array}$} \\
\hline & $\begin{array}{l}\text { Trimetho- } \\
\text { prim }\end{array}$ & Mixture & $\begin{array}{l}\text { Trimetho- } \\
\text { prim }\end{array}$ & Mixture \\
\hline $\begin{array}{l}\text { Organisms sensitive to } \\
\text { both drugs }{ }^{1} \\
\text { Organisms sensitive to } \\
\text { trimethoprim only }{ }^{2}\end{array}$ & $\begin{array}{l}128- \\
>1024 \\
32- \\
>256\end{array}$ & $\begin{array}{l}2-8 \\
32- \\
>128\end{array}$ & $\begin{array}{l}32- \\
128\end{array}$ & $\begin{array}{l}2-8 \\
32- \\
256\end{array}$ \\
\hline
\end{tabular}

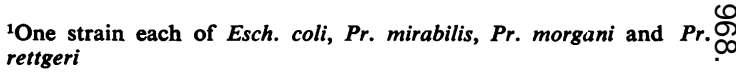

'One strain each of Esch. coli, Pr. mirabilis, Pr. morgani, and Klebsiella

It is at once evident that exposure to rising concentrations of trimethoprim alone produces a large $\mathbb{Q}$ increase in resistance. It was also observed in doing Miles and Misra counts on agar containing different concentrations of trimethoprim that very few but normal colonies of Esch. coli are obtained from af heavy inoculum on medium containing eight to 16 times the MIC for the rest of the culture: these

T A B L E II

DEGREE OF POTENTIATION OF THE ACTION OF TRIMETHOPRIM BY SULPHAFURAZOLE ${ }^{1}$

\begin{tabular}{|c|c|c|c|c|c|c|c|c|c|}
\hline \multirow[t]{2}{*}{ Species } & \multicolumn{2}{|c|}{ Range of MIC $(\mu \mathrm{g} / \mathrm{ml})$} & \multirow{2}{*}{$\begin{array}{l}\text { Ratio } \\
\text { Sulphafurazole: } \\
\text { Trimethoprim }\end{array}$} & \multicolumn{6}{|c|}{$\begin{array}{l}\text { Nos. of Strains Showing Fold Increases in Activity of } \\
\text { Trimethoprim in the Presence of Sulphonamide }\end{array}$} \\
\hline & Sulphafurazole & Trimethoprim & & -2 & -4 & -8 & -16 & -32 & -64 \\
\hline $\begin{array}{l}\text { Staph. aureus } \\
\text { Staph. aureus } \\
\text { Str. pyogenes } \\
\text { Str. pneumoniae } \\
\text { N. gonorrhoeae } \\
\text { H. influenzae } \\
\text { Esch. coli } \\
\text { Klebsiella spp. } \\
\text { Salmonella spp. } \\
\text { Shigella spp. } \\
\text { Pr. mirabilis } \\
\text { Pr. vulgaris } \\
\text { Pr. morgani } \\
\text { Pr. rettgeri } \\
\text { Proteus spp. } \\
\text { Ps. aeruginosa }\end{array}$ & $\begin{array}{c}4-8 \\
512-2048 \\
1-16 \\
2-128 \\
0 \cdot 5-8 \\
0 \cdot 5-64 \\
4-32 \\
8-64 \\
16-128 \\
4-16 \\
4-16 \\
4-16 \\
2-32 \\
16-64 \\
>2000 \\
256-1024\end{array}$ & $\begin{array}{l}0 \cdot 12-0 \cdot 5 \\
0 \cdot 12-0 \cdot 5 \\
0 \cdot 25-0 \cdot 5 \\
0 \cdot 5-2 \\
32-64 \\
0 \cdot 01-0 \cdot 25 \\
0 \cdot 12-0 \cdot 5 \\
0 \cdot 5-1 \\
0 \cdot 06-0 \cdot 25 \\
0 \cdot 03-0 \cdot 5 \\
0 \cdot 5-2 \\
0 \cdot 5-2 \\
0 \cdot 5-2 \\
0 \cdot 5-1 \\
1-8 \\
64-512\end{array}$ & $\begin{array}{r}9: 1 \\
2000: 1 \\
9: 1 \\
9: 1 \\
1: 3 \\
9: 1 \\
9: 1 \\
9: 1 \\
9: 1 \\
9: 1 \\
9: 1 \\
9: 1 \\
9: 1 \\
9: 1 \\
1000: 1 \\
9: 1\end{array}$ & $\begin{array}{r}1 \\
1 \\
3 \\
10 \\
\\
10 \\
1\end{array}$ & $\begin{array}{r}7 \\
3 \\
4 \\
2 \\
14 \\
8 \\
6 \\
4 \\
2\end{array}$ & $\begin{array}{r}5 \\
1 \\
3 \\
12 \\
2 \\
2 \\
6 \\
1 \\
\\
5 \\
2 \\
5 \\
1 \\
2 \\
1 \\
4\end{array}$ & $\begin{array}{l}2 \\
2 \\
3 \\
1 \\
3\end{array}$ & $\begin{array}{l}3 \\
4\end{array}$ & 1 \\
\hline
\end{tabular}


colonies yield progeny with uniform resistance of this degree. Bacterial populations may thus contain a small minority either of resistant variants or of cells capable of mutation to higher resistance.

When the same organisms, originally sensitive to both drugs, and trained to trimephoprim resistance, were tested with the mixture, only small increases were observed: the sulphonamide component was here evidently responsible for inhibition. Similarly when doubly sensitive organisms were trained to both drugs only the same small increases in resistance to the mixture were obtained, and the increase in resistance to trimethoprim was less than after training to this drug alone. Further progress in resistance is evidently blocked by the sulphonamide, sensitivity to which remains unchanged.

When organisms were tested which were trimethoprim-sensitive but sulphonamide-resistant, both forms of training produced large increases in resistance to both trimethoprim and the mixture.

It seems reasonable to hope from these results that treatment with the mixture of infections by organisms sensitive to both drugs will not produce a serious degree of bacterial resistance. This has been borne out by clinical experience so far: increased resistance to trimethoprim has been seen only in two originally sulphonamide-resistant organisms (strains of Klebsiella in which the MIC of trimethoprim rose from 0.2 to 2 and 0.06 to $16 \mu \mathrm{g} / \mathrm{ml}$ ).

EFFECT OF COMPOSITION OF MEDIUM The action of trimethoprim is not antagonized like that of sulphonamides, by $p$-aminobenzoic acid, but other constituents in some culture media which may also be sulphonamide antagonists interfere with it. On such media either no inhibition is produced by a trimethoprim disc (particularly in a culture of a Klebsiella) or an area equal to that of the inhibition zone on a satisfactory medium is occupied by numerous small colonies. Media vary in their content of interfering substances: of those tested DST agar (Oxoid) has a much lower content than blood agar bases 1 or 2 (Oxoid).

The addition of lysed horse blood, as for tests of sulphonamide sensitivity, renders almost any medium suitable for tests of trimethoprim sensitivity. As little as $0.25 \%$ suffices for DST agar, but other media require much more, and an addition of $3 \%$ is advised. Whole blood is ineffective, unless lysis has occurred in it and the medium used requires only a small addition of the neutralizing substance. This substance is heat-labile, and a further addition of lysed blood must be made if chocolate agar is used.

We have found that composition of the medium affects the behaviour of Str. faecalis in a peculiar way. Twenty strains were inhibited by $0 \cdot 06-0 \cdot 25$ $\mu \mathrm{g} / \mathrm{ml}$ trimethoprim on DST agar $+5 \%$ lysed horse blood, but on blood agar base no. 1 with the same addition none were inhibited by $512 \mu \mathrm{g} / \mathrm{ml}$.

ROUTINE SENSITIVITY TESTS Only a disc method is acceptable for routine use, but the definition of its details presents difficulties. Ideally the test should indicate the degree of sensitivity to sulphonamide, trimethoprim, and the combination of the two, the last being a measure of the degree of synergy. This can be attempted as shown in Figure 1. On each of these plates the lower left disc contains sulphafurazole, the lower right trimethoprim, and the upper the same quantities of both drugs.

Synergy can be shown in this test in two ways. The zone of inhibition produced by the combined disc may be larger, as in B and D, both being cultures sensitive to both drugs. These plates also show it in the second way, by a clearly enhanced effect where the zones produced by the individual drugs merge. A and $\mathrm{C}$ are sulphonamide-resistant cultures, and the combined drug inhibition zone is no larger than the trimethoprim, but the latter extends in a remarkable way towards the sulphonamide disc, showing that sulphonamide potentiates the action of trimethoprim, even though the organism is sulphonamideresistant. Unfortunately pictures of this kind depend on exact spacing between the two discs, and there is no means of knowing how far apart they should be to show the effect.

This three-disc test is nevertheless worth while whenever trimethoprim treatment is seriously contemplated, and it is consequently justifiable to devote a plate wholly to this test. On the other hand when the test is one of a series routinely applied, a single combined disc which may be one of a number containing antibiotics etc. applied to the same plate, should give an adequate indication of sensitivity.

The decision on disc content for trimethoprim is difficult, because some organisms are very highly sensitive (MIC $0.06 \mu \mathrm{g} / \mathrm{ml}$ or even less) and inhibition zones are therefore inconveniently large. Yet organisms with an MIC considerably higher than this cause infections known to be susceptible to treatment, and these must also be shown to be sensitive. The content of discs at present in use is $2.5 \mu \mathrm{g}$ and this seems a satisfactory compromise; that of sulphafurazole discs is $50 \mu \mathrm{g}$. Users of discs containing both drugs in these amounts would do well to familiarize themselves with the inhibition zones produced by them in cultures of (1) a trimethoprimsensitive sulphonamide-resistant Pr. morgani; (2) a strain of Esch. coli sensitive to both drugs, in order to have a standard on which to base their reported findings.

The medium used must contain $5 \%$ lysed horse 


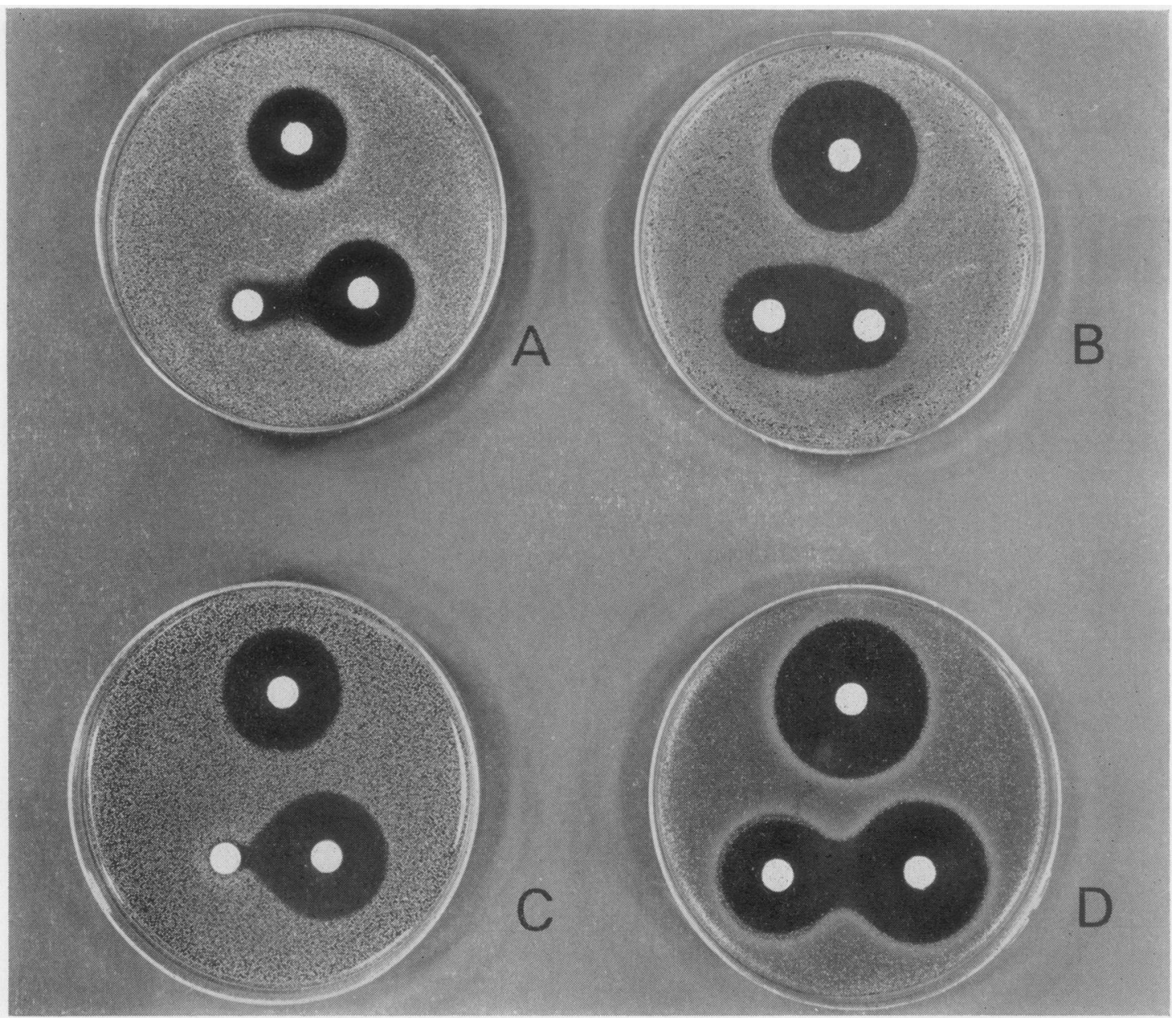

FIG. 1. Disc sensitivity tests. In each plate the bottom left disc contains sulphafurazole, $50 \mu g$; the bottom right trimethoprim, $2.5 \mu \mathrm{g}$; the top right the same amounts of both
$A$. Staph. aureus
$B$. Proteus morgani
$C$. Staph. aureus
D. Esch. coli

blood. Inoculation should preferably be by flooding and draining, and the inoculum must not be too heavy.

BACTERICIDAL ACTION The action of sulphonamides is purely bacteristatic, and this was confirmed with the strains of bacteria and in the culture media used in the experiments now to be briefly described.

Broth containing lysed horse blood and either trimethoprim or sulphafurazole or both was inoculated with one of the following organisms and a small loopful was spread over one fourth of a plate hourly up to seven hours and after 24 hours of incubation. Trimethoprim alone sometimes caused a substantial fall in the viable count (from innumerable to few colonies) but trimethoprim $(1 \mu \mathrm{g} / \mathrm{ml})+$ sulphafurazole $(10 \mu \mathrm{g} / \mathrm{ml})$ sterilized an inoculum of Pr. morgani in five hours, of Pr. rettgeri in six hours, and almost sterilized one of Esch. coli in five hours. A similar but slower effect was seen in a test with Staph. aureus. An elaborate experiment demonstrating bactericidal synergy against $N$. gonorrhoeae is reported elsewhere (Garrod and Waterworth, 1968).

The bactericidal effect exerted by the combination may well be responsible for the rapid improvement ofter seen following its clinical use.

\section{SOME CLINICAL OBSERVATIONS}

Trimethoprim has now been used in the treatment of about 60 cases in this hospital. The following 
brief account of results is intended only to indicate some types of infection in which its use appears to us to merit further study.

CHRONIC BRONCHITIS The combination of trimethoprim and sulphonamide has been most extensively used in this hospital in the treatment of infective exacerbations in chronic bronchitics. Most had been previously treated with ampicillin and tetracyclines, some with chloramphenicol also. In the majority, trimethoprim produced a good initial response with strikingly rapid reduction in the purulence of the sputum. In some cases loss of the initial pathogen was followed by colonization by resistant organisms such as Pseudomonas aeruginosa or Candida species, an example of the characteristic tendency of bronchitics to re-infection.

T.S., a man aged 73 , a known bronchitic for 16 years, required hospital admission nearly every winter. Ampicilin and tetracyclines had been used on numerous occasions and he had also been given steroids. Admitted in an acute exacerbation in September 1966, he was producing copious purulent sputum. Treated initially with ampicillin $1.5 \mathrm{~g}$ daily (intramuscularly and orally) and physiotherapy, his general condition improved but he continued to cough up large volumes of green purulent sputum. Cultures showed that from the onset the infecting organism had been Klebsiella pneumoniae resistant to ampicillin.

His treatment was changed to trimethoprim $250 \mathrm{mg}$ and Gantanol $500 \mathrm{mg}$ twice daily, with a dramatic reduction in the amount and degree of purulence of the sputum. After five days' treatment the patient complained of inability to cough up sputum; this was thought to be because there was none to cough up. A small mucoid specimen obtained at this time yielded a Candida species only.

In this and other patients the effect of this treatment appeared superior than that of any antibiotic in eliminating infection for the time being. Organisms eliminated in other patients include pneumococci and $H$. influenzae. A controlled trial of the treatment is now in progress.

STAPHYLOCOCCAL PNEUMONIA R.D., a man aged 59 years, a chronic bronchitic with cor pulmonale, he presented with purulent bloodstained sputum due to a staphylococcal pneumonia. Before admission he had had two weeks' treatment with tetracyclines, followed by one week of chloramphenicol.

The organism isolated on admission was resistant to benzylpenicillin, streptomycin, tetracycline, chloramphenicol, erythromycin, and lincomycin. Treatment was started with cephaloridine but was changed after two days to cloxacillin plus kanamycin because of the patient's critical condition.

However, though the phage type remained the same (type 84) staphylococci from subsequent sputum specimens were found to be resistant to methicillin and cephaloridine. Treatment was started with trimethoprim $250 \mathrm{mg}$ and Gantanol $500 \mathrm{mg}$ twice daily, previously used in this patient as an outpatient against his infective bronchitis. The pneumonia rapidly resolved and four subsequent sputum specimens were either sterile or yielded coagulase-negative staphylococci only.

This case not only shows the efficacy of trimethoprim in adverse clinical circumstances, but suggests that it is worthy of trial in staphylococcal infections of other kinds.

GRAM-NEGATIVE SEPTICAEMIA E.K., a coloured woman aged 32, had a caesarean section for prolonged labour with a breech presentation performed in Sierra Leone. Fever up to $103^{\circ} \mathrm{F}$ with rigors occurred two days later. A laparotomy was performed and a haematoma evacuated from the left broad ligament. Before transfer to Hammersmith Hospital the patient had been given benzylpenicillin and streptomycin, followed by chloramphenicol, then ampicillin and finally intravenous tetracyclines. On admission she was found to have bacteraemia with a strain of Escherichia coli (non-lactose fermenting variant) resistant to penicillin, ampicillin, streptomycin, tetracyclines, chloramphenicol, and also to cephaloridine, and sensitive only to kanamycin and polymyxins.

The chart (Fig. 2) shows that blood cultures remained positive with this same organism over four weeks, in spite of treatment with benzylpenicillin 12 mega units daily intravenously together with kanamycin $1 \mathrm{~g}$ daily, followed by polymyxin B sulphate $1.5 \mathrm{mega}$ units daily intravenously.

During the course of polymyxin treatment a laparotomy was performed and a large abscess cavity in the left broad ligament was drained. The patient suffered a cardiac arrest in the immediate postoperative period. Following the operation high fever and rigors with positive blood cultures recurred. This was felt to indicate a persisting focus of infection, but this could not be localized and the patient's condition did not warrant a further exploratory operation. Kanamycin and polymyxin $B$, the only antibiotics active against the organism, were given again, this time the polymyxin in the form of the methane-sulphonate. There was again no response, though the organism remained fully sensitive to both antibiotics. Treatment was then changed to trimethoprim $250 \mathrm{mg}$ three times daily with Sulphatriad $6 \mathrm{~g}$ daily, both given by mouth. Vomiting was controlled with phenergan. The patient responded dramatically, her temperature settling to normal over three days and the blood culture becoming negative. No further surgery was required.

T.M., a man aged 55, had a congenital aortic valve lesion, a murmur first being noticed at the age of 11 years. Four days before admission dental filling and scaling was carried out under oral penicillin cover. Two days later he developed fever and rigors. Bacterial endocarditis was diagnosed and after blood cultures had been prepared, treatment was started with intramuscular benzylpenicillin and streptomycin. Following transfer to Hammersmith 


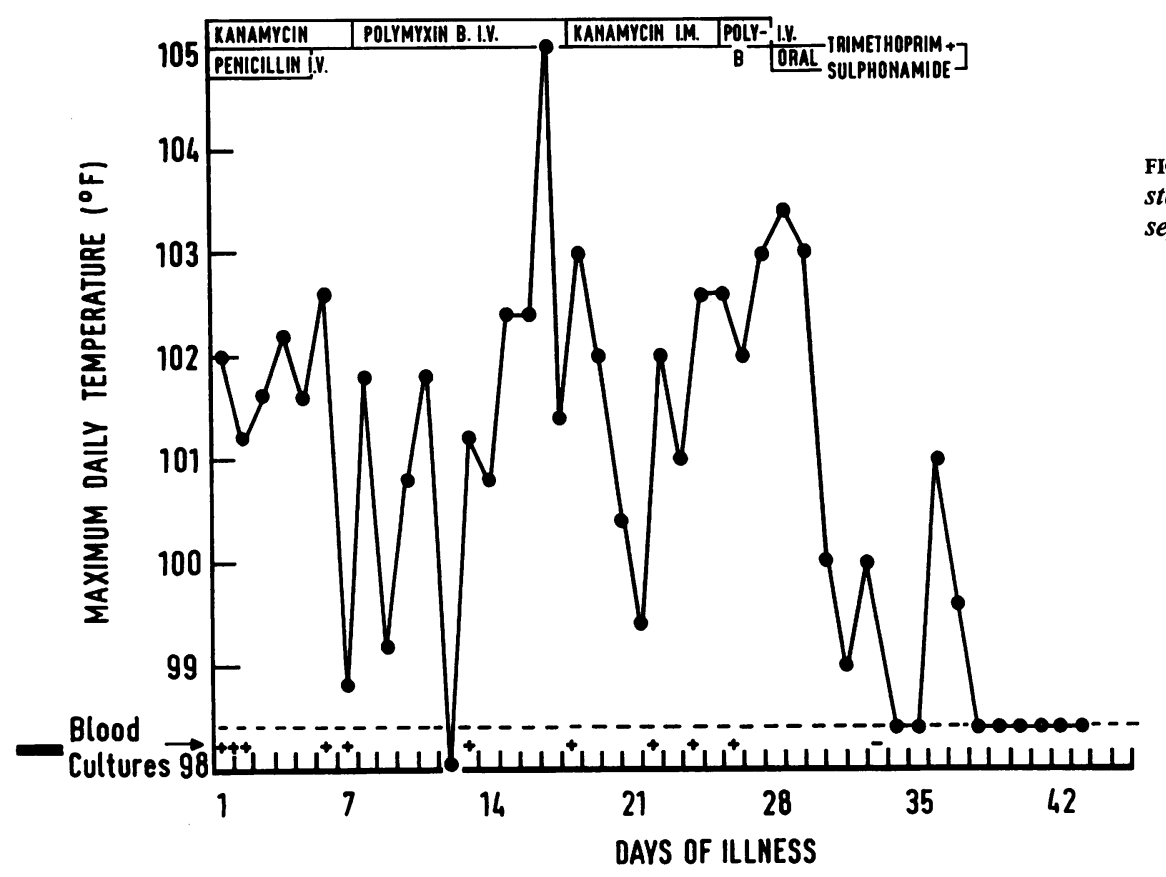

FIG. 2. Chart of later stages of an Esch. coli septicaemia (case E.K.)

Hospital the same treatment was continued by the intravenous route until all blood cultures were found to contain Enterobacter aerogenes, resistant to benzylpenicillin, ampicillin, and cephaloridine, but sensitive to streptomycin, tetracyclines, chloramphenicol, kanamycin, and polymyxins. Treatment was changed to benzylpenicillin, cephaloridine, and kanamycin to cover the possibility of an underlying undiscovered streptococcal infection, for instance with a faecal streptococcus. Such a combination is likely to be bactericidal, a necessity in treating endocarditis. During the next week all bottles of 13 blood cultures grew the same organism after overnight incubation in spite of antibiotic treatment. In the face of this heavy persisting bacteraemia, surgical excision of the valve and prosthetic replacement was considered but rejected. No extracardiac focus to account for the coliform septicaemia could be found. Polymyxin B was now added to the antibiotic regime. The next three blood cultures gave growth from only one of the three bottles, the Robertson's cooked meat medium. All antibiotics were now discontinued except polymyxin, and trimethoprim $250 \mathrm{mg}$ and Gantanol $500 \mathrm{mg}$ were given twice daily with this. The patient's condition continued to deteriorate and he died of the haemodynamic complications of gross acute endocarditis. However, three blood cultures taken after the institution of trimethoprim therapy yielded no growth after three weeks' incubation and only a single colony of Enterobacter was grown from the heart valve removed at necropsy. It appears that trimethoprim plus sulphonamide added to polymyxin proved more effective than either kanamycin or polymyxin alone in spite of the fact that the infecting organism showed the normal level of sensitivity to both drugs (minimum bactericidal concentration: polymyxin 0.25 $\mu \mathrm{g} / \mathrm{ml}$, kanamycin between 2 and $4 \mu \mathrm{g} / \mathrm{ml}$ ).

Three other patients with septicaemia illustrate an apparent defect of this treatment. A Bacteroides $\overline{\bar{O}}$ septicaemia with a liver abscess subsequent to per- 3 foration of the caecum was uncontrolled, and in $\vec{F}$ two patients with $E$. coli septicaemia complicating septic abortion this organism was eliminated but replaced in the blood by a Bacteroides.

URINARY TRACT INFECTIONS The following are typical examples of success and partial failure.

R.S., a man aged 57, a staff member, developed an acute urinary infection and was given ampicillin with no 윽 symptomatic improvement after three days. The treat- $D$ ment was changed to sulphonamides. Bacteriology 윽 showed the infection to be due to a Klebsiella species $\overline{\mathrm{N}}$ resistant to ampicillin and partially resistant to sulphona- $\sigma$ mides, which also failed to produce symptomatic relief $N$ in three days. Within 48 hours of starting trimethoprim $250 \mathrm{mg}$ and Gantanol $500 \mathrm{mg}$ twice daily urinary symp- $\omega$ toms disappeared and the urine was shown to be sterile.

J.B., a woman aged 45 , a case of pyelonephritis, pre- 6 sented with a mixed infection with $E$. coli and $K$. aero- $\overline{\mathscr{D}}$ genes. Both organisms were resistant to sulphonamide but sensitive to trimethoprim. Before this was known $\square$ empirical treatment was started with the mixture, trime- $\bar{O}$ thoprim $250 \mathrm{mg}$ and Gantanol $500 \mathrm{mg}$. The $E$. coli was $\overrightarrow{\mathbb{D}}$ eliminated but a significant growth of Klebsiella persisted $\frac{\rho}{\mathbb{P}}$ and the patient's symptoms remained unchanged. During the course of treatment, which lasted seven days, the 
Klebsiella became more resistant to trimethoprim (MIC before $0.12 \mu \mathrm{g}$; after, $2 \mu \mathrm{g} / \mathrm{ml})$. This patient was subsequently given both polymyxin and gentamicin without effect. A laparotomy showed that she had ureteric obstruction on the right. When this was relieved the urinary infection subsided but recurred four months later.

The case demonstrates the well known difficulty of eradicating urinary infections complicated by obstruction and urinary stasis, using chemotherapeutic agents alone.

These cases also suggest that sulphonamide resistance is not a bar to success from combined treatment. (The appearances in Fig. 1 are proof that a sulphonamide can contribute to the action of trimethoprim despite such resistance.)

\section{DISCUSSION}

The object of this paper is to call wider attention to a drug which we believe to represent a major discovery and to have far-reaching therapeutic possibilities. Independently it is very highly active against many species of bacteria, much more so in terms of MIC than sulphonamides. Its combined action with them is strongly synergic, and differs from that of sulphonamides in being bactericidal. The rapid and decisive therapeutic effect often observed may thus be accounted for.

Apart from infections discussed here, gonorrhoea has recently been shown to be susceptible to treatment by Csonka and Knight (1967). Among those we have studied enterobacterial infections (E. coli, Proteus and Klebsiella) bulk largely. The place of trimethoprim in treating urinary infections caused by these organisms remains to be further defined. We would urge that this treatment be considered early, if not indeed preferred in the first instance to the use of antibiotics, for treating this form of septicaemia. Naturally much further experience is necessary: for example, no one, so far as we are aware, has attempted this treatment in bacteriaemic shock (for which the intravenous preparation of trimethoprim and of the sulphonamide used would evidently be advisable). $H$. influenzae is sensitive, as are other bacteria concerned in bronchial infections, and this is another field meriting further study.

Among Gram-positive coccal infections, those due to group A streptococci and pneumococci stand in no need of any new form of treatment, although according to findings in vitro they should respond well. Staphylococcal infections represent an almost entirely unexplored field in which gratifying results might well be obtained, particularly if the strain is sulphonamide-sensitive.

We are indebted to the Wellcome Foundation for supplies of the drug for therapeutic use, for sensitivity test discs, and for much information and useful discussions, and to our clinical colleagues for permission to refer their patients.

\section{REFERENCES}

Cooper, R. G., and Wald, M. (1964). Med. J. Aust., 2, 93.

Csonka, B. W., and Knight, G. J. (1967). Brit. J. vener. Dis., 43, 161

Drew, C. D. M., Hughes, D. T. D., and Jenkins, G. C. (1967). Proc. $V$ int. Congr. Chemother., Suppl. In the press.

Fowle, A. S. E., Drew, C. D. M., Hughes, D. T. D., and Cassell, M. A (1967). Proc. V int. Congr. Chemother., 1, 293.

Garrod, L. P., and Waterworth, P. M. (1968). Brit. J. vener. Dis. In the press.

Noall, E. W. P., Sewards, H. F. G., and Waterworth, P. M. (1962) Brit. med. J., 2, 1101 .

Roth, B., Falco, E. A., Hitchings, G. H., and Bushby, S. R. M. (1962). J. med. pharm. Chem., 5, 1103.

Schneider, M., Schwarzenberg, L., Caltan, A., Schlumberger, J. R., Amiel, J. L., and Mathé, G. (1965). Presse med., 73, 893.

Steers, E., Foltz, E. L., and Graves, B. S. (1959). Antibiot and Chemother., 9, 307. 